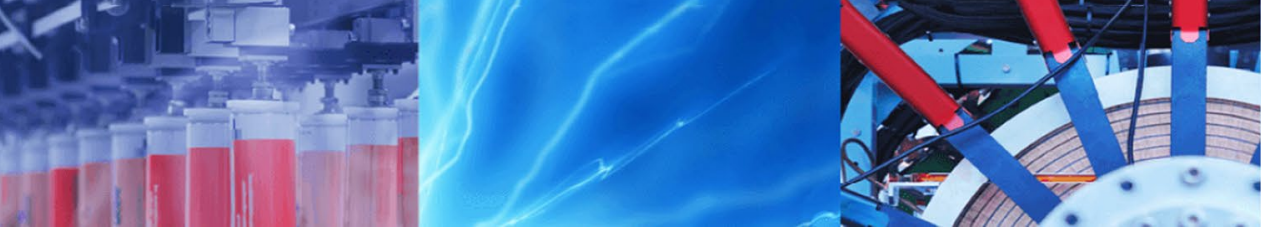

Research Article

\title{
Bioremediation of soils contaminated with petroleum solid wastes and drill cuttings by Pleurotus sp. under different treatment scales
}

\author{
Roberto Romero-Silva ${ }^{1}$ Ayixon Sánchez-Reyes ${ }^{2}$ (1) - Yuletsis Díaz-Rodríguez ${ }^{1} \cdot$ Ramón Alberto Batista-García $^{3}$. \\ Danai Hernández-Hernández ${ }^{1}$ Judith Tabullo de Robles ${ }^{4}$
}

(c) Springer Nature Switzerland AG 2019

\begin{abstract}
Wastes from the oil industry represent one source of soil pollution with a great environmental impact. Both drill cuttings and crude residues are delivered to the soil and produce toxic effects, mainly due to the polycyclic aromatic hydrocarbons. Various bioremediation technologies have been implemented to restore the soil quality and the natural auto depuration capabilities, amongst them: composting, bioaugmentation and biostimulation. These bioremediation techniques promise to be eco-friendlier and cheaper alternatives than other approaches. In this work we have evaluated several strains of Pleurotus sp. for their effect on the bioremediation of oil-contaminated wastes and drill cuttings disposed in storage tanks or in open-air soil lots for many years. Our results support that combined natural attenuation mechanisms and directed fungal biodegradation activities, could be promising strategies to remediate heavily petroleum polluted soils and drilling wastes both at the laboratory and in field conditions. Furthermore, we present data that supports the Pleurotus genus as able to degrade asphaltenes, the most recalcitrant fraction of petroleum. In addition, the annotation of the genome representative of Pleurotus ostreatus revealed clues about the possible enzymatic factors related to the mobilization of carbon from both aromatics and aliphatic derivatives from petroleum hydrocarbons in the genus. This study proposes an approach that at the same time can treat soils contaminated with waste from drill cuttings and bottoms of crude storage tanks.
\end{abstract}

Keywords Bioremediation $\cdot$ Pleurotus $\cdot$ Drilling cuttings $\cdot$ Petroleum wastes $\cdot$ Natural attenuation

\section{Introduction}

The exploitation of petroleum resources is one of the anthropogenic activities with the greatest environmental impact on aquatic and terrestrial ecosystems. Cleaning of crude oil storage tanks and drilling operations, among other activities, produces petroleum wastes that are accumulated in open-air lots, negatively impacting soil quality.
Petroleum-contaminated drill cuttings regularly contain a mix of water, oil or synthetic-based fluids with significant amounts of petroleum hydrocarbons. The hydrocarbon content includes a wide range of saturated and high-molecularweight aromatic compounds [1]. Crude oil and drill cuttings are toxic, mainly due to polycyclic aromatic hydrocarbons (PAH) present in the muds (5-10\%) [2]; and at least sixteen different PAH are alleged cancer-causing agent's [3]. There

Electronic supplementary material The online version of this article (https://doi.org/10.1007/s42452-019-1236-3) contains supplementary material, which is available to authorized users.

Ayixon Sánchez-Reyes, ayixon.sanchez@mail.ibt.unam.mx| ${ }^{1}$ Centro de Investigación del Petróleo, Churruca 481, El Cerro, La Habana, Cuba. ${ }^{2}$ Cátedras Conacyt-Instituto de Biotecnología, Av. Universidad 2001, Col. Chamilpa, 62210 Cuernavaca, Morelos, México. ${ }^{3}$ Centro de Investigación en Dinámica Celular, Instituto de Investigaciones en Ciencias Básicas y Aplicadas, Universidad Autónoma del Estado de Morelos (UAEM), Av. Universidad 1001, Col. Chamilpa, 62209 Cuernavaca, Morelos, México. ${ }^{4}$ Centro de Investigación en Biotecnología, Universidad Autónoma del Estado de Morelos, Av. Universidad 1001, Col. Chamilpa, 62210 Cuernavaca, Morelos, México.

SN Applied Sciences (2019) 1:1209| https://doi.org/10.1007/s42452-019-1236-3

Received: 16 June 2019 / Accepted: 6 September 2019 / Published online: 13 September 2019 
are several physicochemical methods for drill cuttings treatment: cuttings re-injection, microwave drying, and thermal desorption. Unfortunately, these methods have serious technical and environmental challenges, such as expensive implementation, high energy demand, risk of accidental releases to the environment and a high level of pollutant residues. Many biological processes have been investigated to overcome these drawbacks, e.g. composting [4], bioaugmentation [5], or biostimulation [6]. These bioremediation techniques promise to be better alternatives, eco-friendly and money-wise, than physicochemical approaches. Although bioaugmentation (the practice of adding cultured microorganisms for biodegrading soil or water contaminants), has been applied successfully in several studies of petroleum hydrocarbons biodegradation by bacteria, there are few reports of the use of processes that combine degradative activity of indigenous bacteria and the bioaugmentation with fungal specimens in soils contaminated with oil-based drill cuttings. Furthermore, fungi gather valuable metabolic characteristics as they are natural xenobiotic degraders and, many species have been isolated from oil-polluted sources $[7,8]$, although most species of the genus Pleurotus have cosmopolitan origin [9]. They contribute to overall geomicrobial activities that play key roles in the cycling of organic matter and diagenesis [10]. Their ability to be massively cultured on industrial wastes with conventional microbiological techniques makes fungi attractive candidates for soil bioremediation processes.

This paper presents a comprehensive analysis to assess the applicability for large-scale bioremediation processes of several fungal strains, as part of the environmental management and final disposal of pollutants from the Cuban oil industry. The effect of four strains of Pleurotus sp. has been evaluated on the bioremediation of oil-contaminated soils and drill cuttings wastes disposed in storage tanks or in open-air soil lots for years, and three scales were implemented for their study at laboratory, microcosm and field levels. Our results show that several isolates of Pleurotus sp. are able to reduce asphaltenes and resins content in the samples tested, a task that only a few microorganisms can do. Also, we annotated the representative genome of Pleurotus ostreatus in the KEGG database [11], and observed that some sequences of the aromatic compound metabolism showed signatures of functional redundancy within the genome. In addition, these results extend the scope of a prior prepublication posted on bioRxiv server describing our early experimental research findings [12].

\section{Materials and methods}

\subsection{Fungi isolation, culture and identification}

Four isolations belong to Pleurotus sp. were obtained from representative basidiomata collected on different decaying woods pieces collected in May 2010, from a Zoological park in Habana, Cuba. The location coordinates were $23^{\circ} 06^{\prime} 40.6^{\prime \prime} \mathrm{N} 82^{\circ} 23^{\prime} 48.8^{\prime \prime} \mathrm{W}$. In order to obtain axenic cultures, pieces of the fruiting body were inoculated in Petri dishes with Sabouraud Dextrose Agar (BioCen Cat. 4018) and $25 \mu \mathrm{g} . \mu \mathrm{L}^{-1}$ of streptomycin, at room temperature $\left(26 \pm 2{ }^{\circ} \mathrm{C}\right)$ for 7 days. Agar plugs with pure mycelium were passed to new dishes and grown for another 7 days. Besides the evidence offered by the fructification bodies, the isolated strains showed morphological features (mycelia growth pattern and conidial morphology) consistent with the genus Pleurotus. The strains were coded as B-1, B-7, B-10, B-15 and pure cultures were conserved in the Chemistry and Biotechnology Laboratory of the Petroleum Research Center, Cuba.

\subsection{Solid state fermentation (SSF): laboratory scale assay}

Three grams of sugarcane bagasse (particle size $<1.6 \mathrm{~mm}$ ) and 17 grams of soil contaminated with petroleum solid wastes were added to conical flasks of $100 \mathrm{~mL}$ capacity. We sterilized them for $15 \mathrm{~min}$ at $121^{\circ} \mathrm{C}$. A solution of ammonium sulfate $(0.25 \%)$ sterilized independently was used to moisten each flask $(32 \mathrm{~mL})$. As inoculant, we used two agar slants ( $5 \mathrm{~mm}$ in diameter) extracted from the active edge of colony growth of the four Pleurotus strains. The fermentation lasted 15 days in static condition at room temperature $\left(26 \pm 2{ }^{\circ} \mathrm{C}\right)$. Five replicate were used for each treatment, including an abiotic control (without fungal treatment).

\subsection{Hydrocarbon degradation in microcosms}

The microcosm assay was carried out in composters (diameter $35 \mathrm{~cm}$, depth $18 \mathrm{~cm}$ ) with sterilized petroleum solid wastes $(1 \mathrm{~kg})$, sugarcane bagasse $(16 \mathrm{~g})$ and then brought up to $60 \%$ of moisture with ammonium sulfate solution $(0.25 \%)$ sterilized independently. The composters were inoculated with circular sections of mycelia $\left(\sim 20 \mathrm{~cm}^{2}\right)$ from the four Pleurotus strains already described, with 4 fragments for each composter. The incubation period lasted 30 days at room temperature $\left(26 \pm 2{ }^{\circ} \mathrm{C}\right)$ on static regime, with period $(6 \mathrm{~h})$ of sunlight in order to simulate field conditions. The microcosms 
were covered with aluminum foil and the soil was moistened by the addition of $250 \mathrm{~mL}$ sterile distilled water every week until the end of the experiment.

\subsection{Bioaugmentation of parcels contaminated with petroleum solid wastes and drill cuttings using a Pleurotus sp. strain}

Two parcels $(15 \times 15 \times 0.30 \mathrm{~m})$ from a long-time contaminated ( 10 years) region with petroleum solid wastes and drill cuttings, in La Cantera Birama, located on Matanzas province, Cuba; were selected for a field-based bioremediation experiment. First, the soil was manually conditioned by removing the surface layer. The field contained aged hydrocarbon residues and a significant rock content. Then, the parcels were biostimulated by adding sawdust according to [13] and moistened with a natural surfactant solution obtained as a byproduct of the processing of henequen fibers (Agave fourcroydes). Subsequently, one parcel was bioaugmented with a mixture of spores and mycelium in Sabouraud liquid medium, from Pleurotus sp. B-7 strain (10E \pm 06 spores $\left.\mathrm{mL}^{-1}\right)$; and the other parcel was left intact, as a natural attenuation control. No physical barrier was established between the parcels. The specifications for transportation and release of the inoculum were authorized by the Biosecurity Licenses CH 17-P (78) 10 and CH17-P (81) 10 granted by the National Center for Biological Safety of Cuba (CSB). The analytical monitoring of the bioremediation process was assessed by extracting a subset of field topsoil samples ( 10 grams of soil) for chemical and microbiological analysis. The following variables were recorded at 0,30 and 70 days: total petroleum hydrocarbons (TPH) [14], Oils and grease [15], saturated, aromatic, resins and asphaltenic components [16, 17], total nitrogen [18], total phosphorus [14], total microorganism count, hydrocarbon-degrading microorganisms [19].

\subsection{Biodegradation analysis}

The rates of biodegradation expressed as a percentage were determined by monitoring the reduction of petroleum components for all samples at the initial and final stages of each experiment. Uninoculated controls supplemented with contaminated soils samples were always considered. The following equation was used for calculations:

Biodegradation rate $=\frac{(C i-C f)}{C i} \times 100$

where $C i$ indicates initial concentration; $C f$ indicates final concentration.

\subsection{Statistical analysis}

For each experiment, we carried out a completely randomized design. We used Kolmogorov-Smirnov test to check the normality premise and Cochran-Hartley and Bartlett test to check the homogeneity of variance. We used the Duncan test for "a posteriori" means comparison. The ANOVA and two-way joining clustering analysis were assessed using the statistical package Statistica 7.0 StatSoft, Inc. (2004). We give additional data in Online Resource 1.

\subsection{Annotation and analysis of Pleurotus ostreatus representative genome}

The genome representative of Pleurotus ostreatus PC15 (GenBank assembly accession GCA_000697685.1) was selected as a predictive model of the metabolic capabilities of the genus to degrade petroleum hydrocarbons. We downloaded the protein sequences in FASTA format from GenBank and submitted to KEGG's internal annotation tool for KO (KEGG Orthology) number assignment [20]. The resulting file with orthologous assignments was used to map molecular functions and reconstruct metabolic pathways within the KEGG mapper portal. The enrichment of molecular functions belonging to aromatic-hydrocarbons degradation was analyzed by a binomial test, where the abundance of target enzymes in Pleurotus genome was set as $k$ parameter, the total KEGG enzymes needed to complete the corresponding pathway was set as $n$ parameter, and $p$ was estimated as $1 / \mathrm{n}$ for the target enzymes represented by a unique group of orthologs (as with: Phenol 2-monooxygenase (K03380), Amidase (K01426), Salicylate monooxigenase (K00480)). When the target enzymes were represented by several groups of orthologs, we estimated p parameter as: $\Sigma \mathrm{KO} / \mathrm{n}$. A group of orthologs on KEGG Database is represented by a KO identifier and corresponds to groups of highly similar experimentally characterized genes and proteins.

\section{Results and discussion}

\subsection{Bioremediation of soils contaminated with petroleum solid wastes (lab scale)}

In order to characterize the petroleum-based hydrocarbon content in the soil at the beginning of the experiment, the samples were subjected to an initial analysis by standard laboratory methods for the fractionation of petroleum (Table 1). The soil samples were rich in compounds that primarily come from crude oil, being the resin and the oils and grease, the major fractions with a content 
Table 1 Initial characterization of soils contaminated with petroleum solid wastes in laboratory scale experiment

\begin{tabular}{|c|c|c|c|c|c|c|}
\hline Treatments & $\begin{array}{l}\text { Oils and } \\
\text { grease } \\
\left(\mathrm{mg} \mathrm{kg}^{-1}\right)\end{array}$ & $\mathrm{TPH}\left(\mathrm{mg} \mathrm{kg}^{-1}\right)$ & Saturateds $\left(\mathrm{mg} \mathrm{kg}^{-1}\right)$ & Aromatics $\left(\mathrm{mg} \mathrm{kg}^{-1}\right)$ & Resins $\left(\mathrm{mg} \mathrm{kg}^{-1}\right)$ & $\begin{array}{l}\text { Asphaltenic com- } \\
\text { ponents }\left(\mathrm{mg} \mathrm{kg}^{-1}\right)\end{array}$ \\
\hline Abiotic control & $3.62 \mathrm{E}+04$ & $8.74 \mathrm{E}+03$ & $4.81 \mathrm{E}+03$ & $4.19 \mathrm{E}+03$ & $2.69 \mathrm{E}+04$ & $5.75 \mathrm{E}+03$ \\
\hline Pleurotus sp. B-1 & $3.92 \mathrm{E}+05$ & $6.55 \mathrm{E}+04$ & $1.00 \mathrm{E}+04$ & $5.40 \mathrm{E}+05$ & $1.09 \mathrm{E}+05$ & $8.87 \mathrm{E}+04$ \\
\hline Pleurotus sp. B-7 & $2.34 \mathrm{E}+05$ & $3.70 \mathrm{E}+04$ & $9.53 \mathrm{E}+03$ & $4.72 \mathrm{E}+04$ & $7.91 \mathrm{E}+04$ & $1.81 \mathrm{E}+04$ \\
\hline Pleurotus sp. B-10 & $2.15 \mathrm{E}+05$ & $5.19 E+04$ & $5.17 \mathrm{E}+03$ & $5.07 \mathrm{E}+05$ & $4.63 \mathrm{E}+04$ & $4.20 \mathrm{E}+04$ \\
\hline Pleurotus sp. B-15 & $9.16 \mathrm{E}+04$ & $1.11 \mathrm{E}+05$ & $3.99 \mathrm{E}+03$ & $6.91 \mathrm{E}+05$ & $2.11 \mathrm{E}+05$ & $1.14 \mathrm{E}+05$ \\
\hline
\end{tabular}

The numerical values represent the average of five replicates per treatment

of $104 \mathrm{mg} \mathrm{kg}^{-1}$ in average. The total petroleum hydrocarbons, saturated, aromatics and asphaltenic components oscillated in the $103 \mathrm{mg} \mathrm{kg}^{-1}$ order. This confirmed that complex mixtures of hydrocarbons derived from crude oil composed almost exclusively the soil samples. After 15 days of treatment with four strains of the basidiomycete Pleurotus sp. (as described in MM) we observed that all of the strains tested decreased the content of several of the oil fractions contained in the polluted soil, in contrast to the abiotic control for which no significant change was detected. The highest degradation rates were reached for saturated hydrocarbons $(36 \%, 41.6 \%, 54.4 \%$ and $53.56 \%$ for the B-1; B-7; B-10 and B-15 strains, respectively) (Fig. 1). The resins (maximum biodegradation of $40.5 \%$ by $B-10$ strain), and oils and grease (maximum biodegradation of $46.34 \%$ by B-15 strain) fractions were degraded by all strains. However, the aromatic fraction was highly elusive to biodegradation, with just $9.2 \%$ achieved by B-7 strain. Remarkably, we observed asphaltenes biodegradation in the experiment, being B-7 the strain with the higher biodegradation rate $(46.45 \%)$ followed by B-10 strain with 21 . $6 \%$. There is very little evidence of fungi that can degrade asphalts and resins; to date, some examples have been described in detail e.g., the ascomycetes Neosartorya fischeri (15.5\% asphaltene biodegradation in several weeks)
[21], Pestalotiopsis sp. (77\% in 30 days) [22] and recently the basidiomycete Daedaleopsis sp. (88\% in 30 days) [23]. Asphaltenes biodegradation rates achieved by Pleurotus sp. B-7 and B-10 are superior compared with Neosartorya fischeri, and they are capable to reach five times more resins degradation compared to Daedaleopsis sp. in significantly lesser time. Pleurotus sp. B-7 was the only strain capable to modify all fractions in the polluted soil, a remarkable fact considering the petroleum hydrocarbons chemical complexity. For example, the resins influence the structural stability of petroleum, asphaltenes contain the highest molecular weight constituents in the crude [24], and aromatic compounds are very stable and resistant to biological degradation; these factors play a major role preventing biodegradation processes by microorganisms therefore, finding microbes capable to degradation of these fractions is valuable for the development of effective bioremediation strategies. These findings are not uncommon, for several studies support the role of Pleurotus for bioremediation of petroleum hydrocarbon contaminants in soil [25-27]. The degradative activity is often associated with the ability of fungi to produce extracellular hydrolases and oxidoreductases [28]. We conclude that Pleurotus sp. B-7 is a good candidate for deeper studies in bioremediation process.
Fig. 1 Biodegradation rates (\%) for soil samples contaminated with petroleum solid wastes during 15 days of treatment with four strains of Pleurotus sp. $(n=5)$

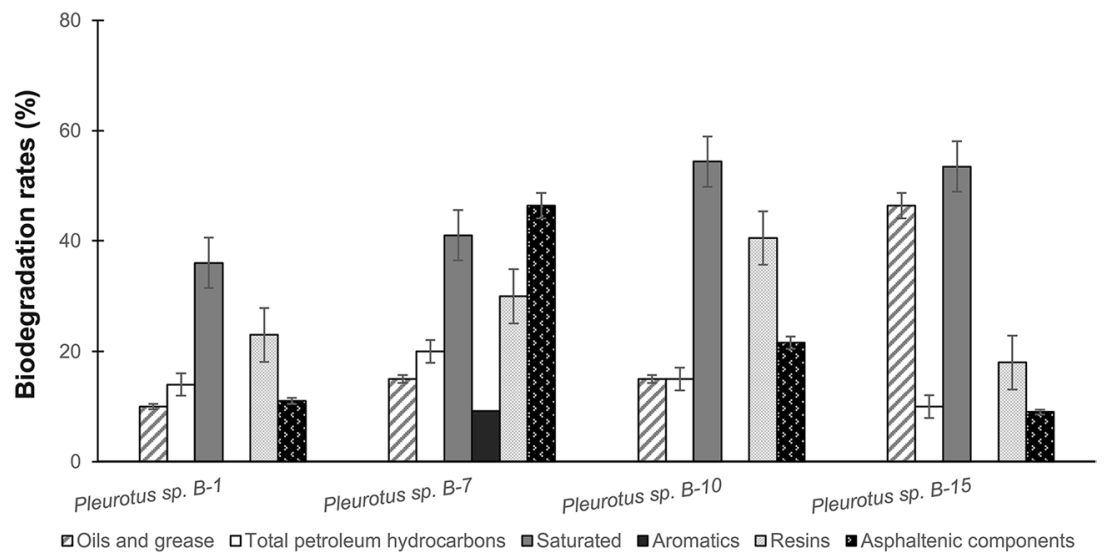




\subsection{Microcosm bioremediation of soils contaminated with petroleum solid wastes}

To scale up the laboratory soil biodegradation experiment, we carried out a microcosm soil biodegradation study for 30 days. The treatments assessed were: a non-sterile natural attenuation control (to supervise natural ability for intrinsic soil remediation in biostimulation conditions); Pleurotus sp. strains in contaminated soil as described in $\mathrm{MM}$; and appropriate sterilized controls to assess abiotic degradation. The natural attenuation treatment achieved significant biodegradation for all fractions in the polluted soil (maximum biodegradation for saturated hydrocarbons $30.6 \%)$, except for asphaltenes for which no biodegradation was detected, reinforcing the fact that native microorganisms are rarely capable of asphaltenes degradation (Fig. 2). Biodegradation by natural attenuation is not unusual, due to indigenous degrader microorganisms in soil samples with potential effect in intrinsic bioremediation $[29,30]$. However, an effect of biostimulation should not be discarded since in real field conditions the nutritional status can be that of oligotrophy.

Pleurotus sp. B-1 could not degrade asphalts nor resins in the microcosm in contrast to our laboratory experiment, which showed a modest behavior at this respect (11-23\%). Pleurotus sp. B-7 and B-15 degrade resins fraction considerably more than any other treatment, and all fungal strains degraded the aromatics compounds, contrasting with the laboratory experiment. These results suggest that resin degradation is a consistent process in the strains studied, and again the rates are higher than those for other basidiomycete [23]. Pleurotus sp. B-10 and B-15 degrade aromatic fractions in a similar extension $\sim 53.4-59.9 \%$ and significantly more than any other treatment. Maybe the aromatics fractions become more biodegradable when longer degradation times apply to the process. Pleurotus sp. B-7 was the only one that degraded all fractions, even asphalts $(40.6 \%)$, which are elusive to degradation by other treatments. The concentration of contaminants for the abiotic control by the end of the assessment showed no significant differences with the initial concentrations (in average $4.2 \mathrm{E}+04 \mathrm{mg} \mathrm{kg}^{-1}$ versus $3.9 \mathrm{E}+04 \mathrm{mg} \mathrm{kg}^{-1}$; standard error $\sim 0.06 \%$ ), suggesting that abiotic mechanisms like volatilization or dilution may not significantly contribute to degradation in these assays [31]. These observations indicated that fungal treatment improved the biodegradation of recalcitrant fractions like aromatics, resins and asphaltenes compared to natural attenuation in the polluted soil. Furthermore, B-7 strain excels once again as a compelling candidate to perform escalated soil bioremediation studies in order to overcome natural attenuation shortcomings.

\subsection{Bioaugmentation of a field soil contaminated with petroleum solid wastes and drill cuttings with Pleurotus sp. B-7 strain}

Pleurotus sp. B-7 was selected as study model for a real field scale bioaugmentation experiment, since it was the strain with better biodegradation performance in both the laboratory and in the microcosm experiments. Before the bioaugmentation treatment, the soil was conditioned as described in $\mathrm{MM}$; a total of $10 \mathrm{~L}$ of the fungal inoculum was spread on the polluted soil surface. The selected soils had relatively high concentrations of petroleum solid wastes. At the beginning of experiment, the contaminant levels and hydrocarbon degrading microorganism count were quite similar for control and treated parcel according to $F$ test $(P$ value $>0.05)$, suggesting a similar potential for natural attenuation in both sites (Fig. 3a). Regardless of the treatment, the main effects were observed after 70 days in terms of reducing pollutants. We confirmed this by the presence of only two statistically different homogeneous groups (days 0 and 70) (Fig. 4), clustered respect to the temporal dynamics of degradation [Oils and grease Duncan test $P$ value: 0.00 ; TPH Duncan test $P$ value: 0.01 ;
Fig. 2 Biodegradation rates (\%) achieved by four Pleurotus sp. strains and a natural attenuation control in soil microcosm bioremediation assay for 30 days $(n=2)$

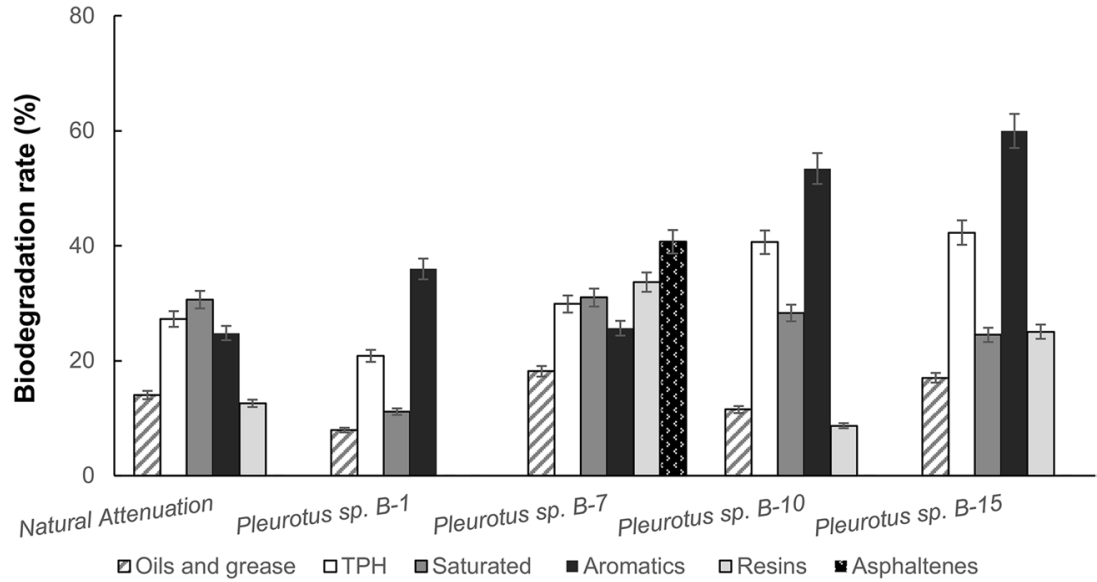

SN Applied Sciences A SPRINGER NATURE journal 

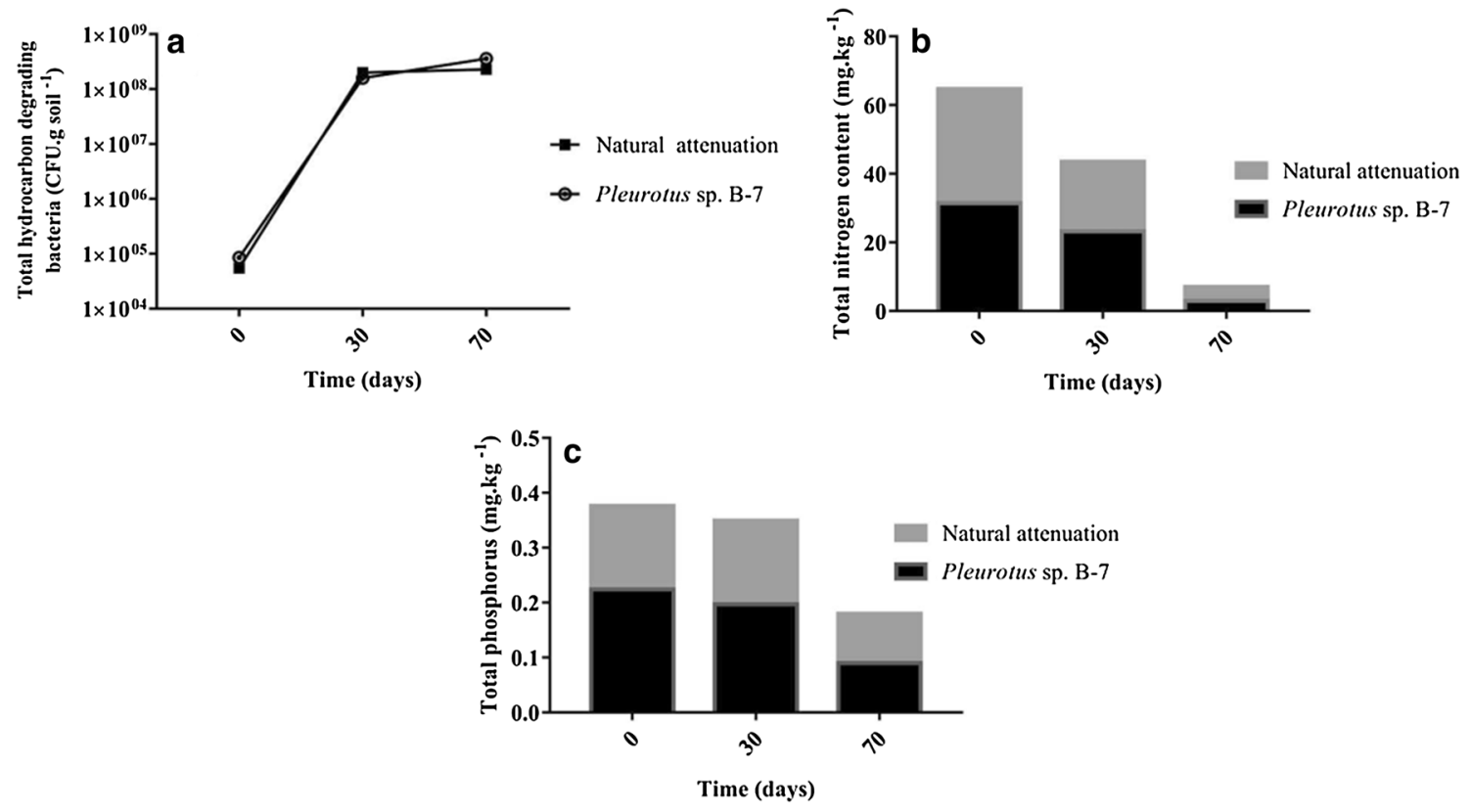

Fig. 3 Microbial count, nitrogen and phosphorus levels in natural attenuation control and B-7 treated parcels. Total hydrocarbon-degrading bacteria (a), total nitrogen (b), total phosphorus $(\mathbf{c})$

Fig. 4 Two-way joining graph of the oil-fractions concentration $\left(\mathrm{mg} \mathrm{kg}^{-1}\right)$ in the field assay for the natural attenuation control and B-7 strain during 0,30 and 70 days of treatment (left side on the heat map). Significant temporal differences between treatments are clustered in the right side dendrogram homogeneous groups (see text for $P$ values details and Online Resource 1)

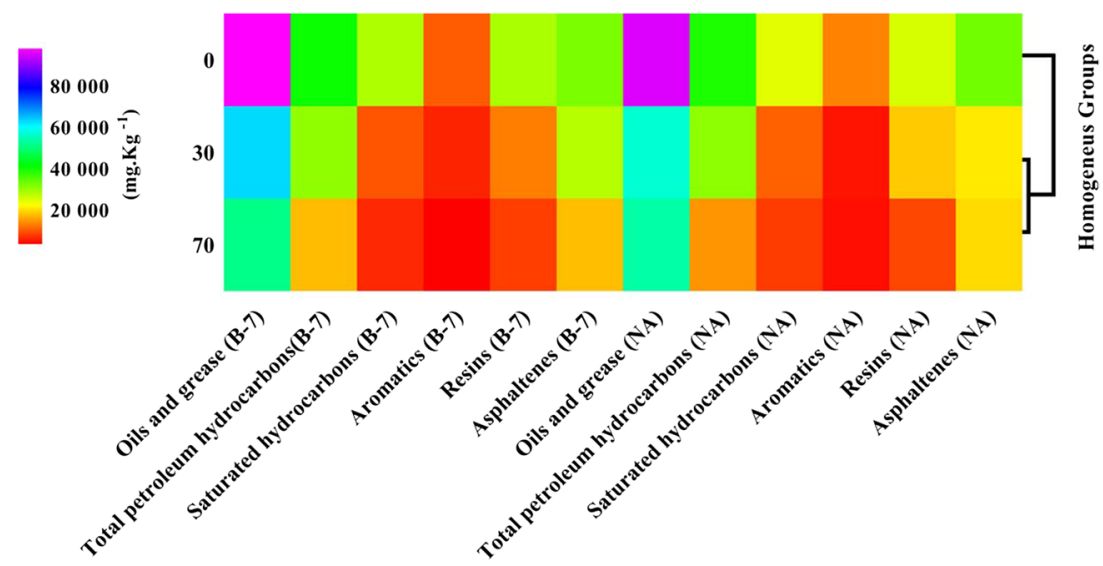

Saturated hydrocarbons Duncan test $P$ value: 0.03 ); Resins Duncan test $P$ value: 0.01 ; Asphaltenic components Duncan test $P$ value: 0.01 ( $a: 0.05$ )] Online Resource 1. Interestingly, at 70 days of treatment the Resins, Saturated and Aromatics-hydrocarbons reached accepted levels according to National Standardization Body of the Republic of Cuba (NC 819: 2017; NC 1263: 2018) $\left(10,000 \mathrm{mg} \mathrm{kg}^{-1}\right)$. However, this period was not enough to reduce Oils and grease, or Asphaltenes up to standards accepted levels. Probably the high initial content of Oils and grease in treated parcels, interfered drastically with the microbial metabolic processes due to its diverse and complex chemical composition (coming from aged fatty matter, sulfur compounds, and organic pigments) [32]. Thus, longer treatments may be necessary for accomplishing the oilpollutants levels in impacted soils, required by normativity. Except for TPH, resins and asphaltenes, at 70 days there were no differences between B-7 and attenuation control. The percentage of resins removal achieved by the inoculum and the control, amount to $56 \%$ and $27 \%$ respectively, while the asphaltenes amounted to degrade a maximum of $14 \%$ in B-7 treatment. These findings suggest a greater resins and asphaltenes biodegradation in the parcel with the fungal inoculum, although the contribution of indigenous microbiota is not ruled out, for example, there was a significant increase in the biodegraders count with the B-7 treatment $\left(8.50 \mathrm{E}+04 \mathrm{CFU}\right.$ g soil ${ }^{-1}$ at 0 day and $3.55 \mathrm{E}+08$ CFU g soil ${ }^{-1}$ at 70 day) (Fig. 3a). This 
increase in four magnitude orders may be related to nutrient biostimulation applied to the treated parcel.

In the parcel's topsoil, the total phosphorus concentrations were extremely low (attenuation control $0.152 \mathrm{mg} \mathrm{kg}^{-1}, \mathrm{~B}-7$ treatment $0.224 \mathrm{mg} \mathrm{kg}^{-1}$ ) at the beginning of the experiment (Fig. 3c), maybe due to the historical characteristics of the field, intrinsically dry, geologically young, little fertile with sparse vegetation mostly composed by Gramineae, spiny crawling plants like Ricinus communis. After 70 days, we noticed a decrease of phosphorous to almost undetectable levels $\left(\sim 0.09 \mathrm{mg} \mathrm{kg}^{-1}\right)$. The total nitrogen content in both plots also suffered a significant decrease over 70 days (Fig. 3b), maybe as a response to the increased metabolic demands of autochthonous and aloctone populations. Phosphorus and nitrogen are essential nutrients required by the microorganisms in the synthesis of cellular structures and for maintenance of adequate metabolic equilibria. The low levels detected in this study may be caused by a weak ability to release parent material rock-derived, like phosphorus, or by sequestration effects mediated by hydrophobic soil matrix contaminants [33]. This suggest that biostimulation plays an important role in bioremediation so maybe it should be considered for treatments at field level by adding nutrients every 70 days (in the case of this study).

Several reports suggest that the Pleurotus genus can effectively degrade petroleum hydrocarbons in the presence of diverse indigenous microflora [27, 34]. In this study, we tested the behavior of four strains of Pleurotus sp. on the degradation of polluted soils with petroleum hydrocarbons and drill cuttings. Our experimental approximation contemplated several scales to select the strain with the best performance in the bioremediation of contaminated soil. Finally, the selected strain (B-7) was tested in the field against a natural attenuation control in order to evaluate its possible use on an industrial scale to the bioremediation of soils impacted with wastes from the petroleum industry. Our strictly controlled laboratory and microcosm studies yielded promising results for biodegradation of the most of the hydrocarbon fractions in crude oil and waste. Furthermore, the field study achieved significant decrease of certain contaminants to acceptable levels at 70 days, according to the Cuban standards for crude oil residues and water-based drilling cuttings treatment $\left(<10,000 \mathrm{mg} \mathrm{kg}^{-1}\right.$ : NC 819: 2017 and NC 1263: 2018). As other studies have pointed out, the combination of several bioremediation strategies could improve the hydrocarbon removal $[35,36]$. Remarkably, asphaltenic components in the polluted soils, were consistently modified by Pleurotus B-7 in the different experiments performed, supporting the possibility to implement an asphalt bioremediation scheme with this strain. However, these kinds of realistic field approaches require extensive environmental monitoring to weigh the real effectiveness of the soil bioremediation process in order to meet international standards. This study is the first large-scale approach to clean up soils contaminated with petroleum hydrocarbons through combined natural attenuation and bioaugmentation in the Cuban oil industry and confirms that long-term monitoring is a necessary condition in the current efforts for bioremediation of petroleum hydrocarbons polluted soils.

\subsection{Genomics bases for petroleum hydrocarbon degradation in Pleurotus}

We annotated the genome representative of Pleurotus ostreatus PC15 (GenBank assembly accession GCA_000697685.1) to explore the genetic bases that allow degrading petroleum hydrocarbons within Pleurotus genus. KEGG's annotation process revealed that several molecular functions hydrocarbon-related were significantly enriched given the abundance of sequences assigned to specifics KEGG Orthology (KO) (Table 2) (see Online Resource 2 for a complete KO list assignments). For example, phenol 2-monooxygenase, and salicylate monooxigenase increased abundance, could be an adaptive dosage response, that allows contend with the degradation of aromatic hydrocarbons derived from crude oil, like toluene, styrene and naphthalene relatives, increasing survival capabilities under selective pressure [37-39]. The presence of an almost complete pathway to degrade alkane-like compounds in the genome of $P$. ostreatus (Fig. 5), suggests a plausibly strategy to degrade

Table 2 Enriched molecular functions abundance for hydrocarbons biodegradation deduced from representative genome of Pleurotus ostreatus PC15 according KEGG annotations

\begin{tabular}{|c|c|c|c|c|c|}
\hline Enzyme & Abundance & $\mathrm{KO}^{\mathrm{a}}$ & $P$ value & $\begin{array}{l}\text { Benjamini-Hochberg } \\
\text { adjusted } P \text { value }\end{array}$ & Reference pathway \\
\hline Phenol 2-monooxygenase (EC:1.14.13.7) & 4 & K03380 & 0.004584 & 0.0057 & Toluene degradation \\
\hline Amidase (EC:3.5.1.4) & 5 & K01426 & 0.000177 & 0.00029 & Styrene degradation \\
\hline Salicylate monooxigenase (EC:1.14.13.1) & 11 & K00480 & $<0.000001$ & $2.49 \mathrm{E}-06$ & Naphthalene degradation \\
\hline
\end{tabular}

${ }^{\mathrm{a}} \mathrm{KO}$ identifier represent an entry of functional orthologues linked with experimental evidence of functionally characterized sequence data 
Fig. 5 Alkane-like compounds degradation pathway reconstructed in Pleurotus ostreatus genome according to KEGG reference pathway (branch of fatty acid degradation). Green boxes indicate orthologous present in the genome

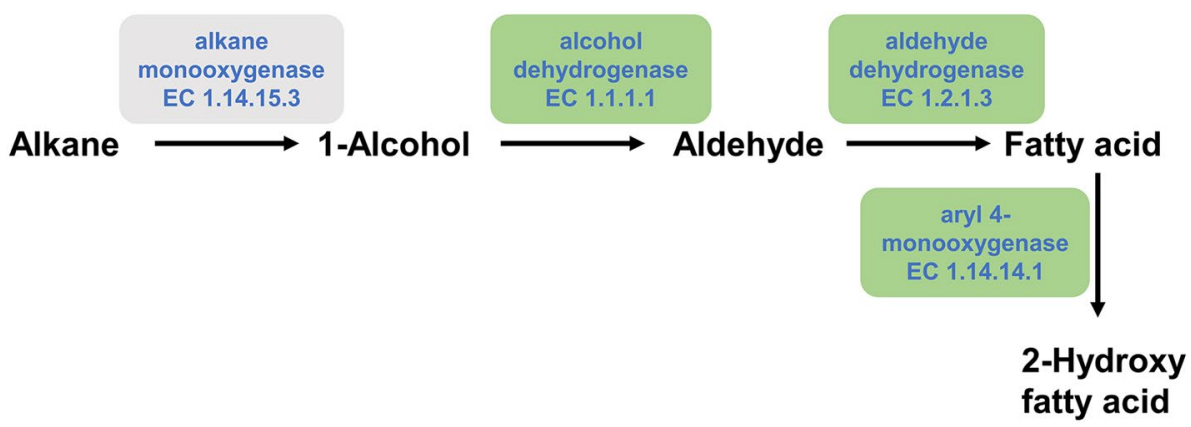

aliphatic hydrocarbons, and could explain the high efficiency in the degradation of saturated fractions reported in this study. It's worth mentioning a coding sequence for aryl 4-monooxygenase (EC 1.14.14.1), member of the cytochrome $\mathrm{P} 450$ system, enzyme related with the oxidation of polycyclic aromatics hydrocarbons [21]. These observations suggest that Pleurotus possesses a metabolic potential that allows it to fill niches related to the degradation of petroleum hydrocarbons. However, more studies are needed to map the functionality of most Pleurotus genes, which lack functional annotation.

\section{Conclusions}

One drawback in bioremediation processes lies in achieving comparable results in laboratory as in the field. Although selected and adapted microbial strains are useful in hydrocarbon biodegradation, not all fractions are degraded in similar extension, the combination of different strategies becomes necessary in order to significantly reduce contaminant levels under realistic field conditions. Our results point toward a combined use of bioaugmentation and natural attenuation with the purpose of obtaining improved outcomes in bioremediation processes. The genus Pleurotus contains a genetic potential still poorly explored, however functional annotation analysis such as the one developed in this study could help to disclose new metabolic functions useful in bioremediation. Currently, we are carrying out studies on this site to understand how autochthonous microbial communities interact in the hydrocarbon-degradation processes through metagenomic approaches. It is worth to highlight the isolation of a very efficient strain of Pleurotus capable of asphaltenes degradation (B-7 strain), since very few organisms can achieve this capacity.

Acknowledgements We thank to Unión Cuba-Petróleo (CUPET) for the financial support; and to Jorge Luis Folch-Mallol and Itzel Gaytán for his helpful comments.
Funding This work was supported by the Unión Cuba-Petróleo (CUPET) through project 2416 granted to Centro de Investigación del Petróleo, Cuba.

Data availability Statistical and genomic annotation datasets generated during the current study are available on the Online Resource described on this paper. Other data are available from the corresponding author on reasonable request.

\section{Compliance with ethical standards}

Conflict of interest The authors declare that they have no conflict of interest.

\section{References}

1. Broni-Bediako E, Amorin R (2010) Effects of drilling fluid exposure to oil and gas workers presented with major areas of exposure and exposure indicators. Res J Appl Sci Eng Technol 2:710-719

2. Petri I, Pereira MS, dos Santos JM et al (2015) Microwave remediation of oil well drill cuttings. J Pet Sci Eng. https://doi. org/10.1016/j.petrol.2015.07.022

3. Larsson M, Hagberg J, Rotander A et al (2013) Chemical and bioanalytical characterisation of PAHs in risk assessment of remediated PAH-contaminated soils. Environ Sci Pollut Res. https://doi. org/10.1007/s11356-013-1787-6

4. Ahmadi M, Dashtestani M, Takdastan A et al (2016) Data on biodegradation of total petroleum hydrocarbons using co-composting of cow manure/oily drill wastes. Data Brief. https://doi. org/10.1016/j.dib.2016.10.008

5. Rezaei Somee M, Shavandi M, Dastgheib SMM, Amoozegar MA (2018) Bioremediation of oil-based drill cuttings by a halophilic consortium isolated from oil-contaminated saline soil. 3 Biotech. https://doi.org/10.1007/s13205-018-1261-8

6. Kogbara RB, Ogar I, Okparanma RN, Ayotamuno JM (2016) Treatment of petroleum drill cuttings using bioaugmentation and biostimulation supplemented with phytoremediation. J Environ Sci Heal Part A Toxic/Hazard Subst Environ Eng. https://doi. org/10.1080/10934529.2016.1170437

7. Dantán-González E, Vite-Vallejo O, Martínez-Anaya $C$ et al (2008) Production of two novel laccase isoforms by a thermotolerant strain of Pycnoporus sanguineus isolated from an oil-polluted tropical habitat. Int Microbiol. https://doi. org/10.2436/20.1501.01.56

8. Marchand C, St-Arnaud M, Hogland W et al (2017) Petroleum biodegradation capacity of bacteria and fungi isolated from 
petroleum-contaminated soil. Int Biodeterior Biodegrad. https ://doi.org/10.1016/j.ibiod.2016.09.030

9. Cohen R, Persky L, Hadar Y (2002) Biotechnological applications and potential of wood-degrading mushrooms of the genus Pleurotus. Appl Microbiol Biotechnol. https://doi.org/10.1007/ s00253-002-0930-y

10. Ehrlich $\mathrm{H}$ (2006) Geomicrobiology: relative roles of bacteria and fungi as geomicrobial agents. In: Gadd G (ed) Fungi in biogeochemical cycles. Cambridge University Press, Cambridge, pp 1-27. https://doi.org/10.1017/CBO9780511550522.002

11. Kanehisa M, Goto S, Sato Y et al (2012) KEGG for integration and interpretation of large-scale molecular data sets. Nucleic Acids Res. https://doi.org/10.1093/nar/gkr988

12. Romero-Silva R, Reyes AS, Diaz-Rodriguez Y et al (2019) Bioremediation of soils contaminated with petroleum solid wastes and drill cuttings by Pleurotus sp. strains under different treatment scales. bioRxiv. https://doi.org/10.1101/588673

13. Díaz-Díaz Miguel Ángel, Rivas-Trasancos Lester, León-Barrios Maydeibys, Acosta-Sánchez J (2018) Material absorbente para recogida de hidrocarburos en derrames en aguas y suelos. Rev Cuba Química 30:289-298

14. APHA A-W (1998) Standard methods for the examination of water

15. Environmental Protection Agency (EPA) (1999) Guidelines establishing test procedures for the analysis of oil and grease and non-polar material under the Clean Water Act and Resource Conservation and Recovery Act; Final Rule. Fed Regist

16. García-Rivero M, Saucedo-Castañeda G, Gutiérrez-Rojas M (2007) Organic solvents improve hydrocarbon desorption and biodegradation in highly contaminated weathered soils. J Environ Eng Sci. https://doi.org/10.1139/s06-061

17. Drews A (1998) Manual on hydrocarbon analysis. ASTM International, West Conshohocken. https://doi.org/10.1520/ MNL3-6TH-EB

18. Gomez-Taylor M (2001) Total Kjeldahl nitrogen in water and biosolids by automated colorimetry with preliminary distillation/ digestion. https://www.epa.gov/sites/production/files/2015-10/ documents/method_1687_draft_2001.pdf. Accessed Jan 2019

19. Margesin R, Labbé $D$, Schinner F et al (2003) Characterization of hydrocarbon-degrading microbial populations in contaminated and pristine Alpine soils. Appl Environ Microbiol. https:// doi.org/10.1128/AEM.69.6.3085-3092.2003

20. Kanehisa M, Sato Y, Morishima K (2016) BlastKOALA and GhostKOALA: KEGG tools for functional characterization of genome and metagenome sequences. J Mol Biol 428:726-731. https:// doi.org/10.1016/J.JMB.2015.11.006

21. Hernández-López EL, Perezgasga L, Huerta-Saquero A et al (2016) Biotransformation of petroleum asphaltenes and high molecular weight polycyclic aromatic hydrocarbons by Neosartorya fischeri. Environ Sci Pollut Res. https://doi.org/10.1007/ s11356-016-6277-1

22. Yanto DHY, Tachibana S (2013) Biodegradation of petroleum hydrocarbons by a newly isolated Pestalotiopsis sp. NG007. Int Biodeterior Biodegrad. https://doi.org/10.1016/j.ibiod .2013.09.008

23. Pourfakhraei E, Badraghi J, Mamashli F et al (2018) Biodegradation of asphaltene and petroleum compounds by a highly potent Daedaleopsis sp. J Basic Microbiol. https://doi. org/10.1002/jobm.201800080

24. Andersen SI, Speight JG (2001) Petroleum resins: separation, character, and role in petroleum. Pet Sci Technol. https://doi. org/10.1081/LFT-100001223

25. Harms H, Schlosser D, Wick LY (2011) Untapped potential: exploiting fungi in bioremediation of hazardous chemicals. Nat Rev Microbiol. https://doi.org/10.1038/nrmicro2519
26. Sukor MZ, Yin CY, Savory RM, Abdul-Talib S (2012) Biodegradation kinetics of naphthalene in soil medium using Pleurotus ostreatus in batch mode with addition of fibrous biomass as a nutrient. Bioremediat J. https://doi.org/10.1080/10889 868.2012.687417

27. Mohammadi-Sichani MM, Assadi MM, Farazmand A et al (2017) Bioremediation of soil contaminated crude oil by Agaricomycetes. J Environ Health Sci Eng. https://doi.org/10.1186/s4020 1-016-0263-x

28. Varjani SJ, Upasani VN (2017) A new look on factors affecting microbial degradation of petroleum hydrocarbon pollutants. Int Biodeterior Biodegrad. https://doi.org/10.1016/j.ibiod .2017.02.006

29. Lee DW, Lee $\mathrm{H}$, Kwon BO et al (2018) Biosurfactant-assisted bioremediation of crude oil by indigenous bacteria isolated from Taean beach sediment. Environ Pollut. https://doi. org/10.1016/j.envpol.2018.05.070

30. Lv H, Su X, Wang $Y$ et al (2018) Effectiveness and mechanism of natural attenuation at a petroleum-hydrocarbon contaminated site. Chemosphere. https://doi.org/10.1016/j.chemospher e.2018.04.171

31. Al-Hawash AB, Dragh MA, Li S et al (2018) Principles of microbial degradation of petroleum hydrocarbons in the environment. J Aquat Res, Egypt. https://doi.org/10.1016/j.ejar.2018.06.001

32. Pawlak Z, Rauckyte T (2008) Oil, grease and used petroleum oil management and environmental economic issues. J Achiev Mater Manuf Eng 26:11-17

33. Eschenbach A, Mescher H, Wienberg R, Mahro B (2001) Humification of PAH and TNT during bioremediation - evaluation of long term risk and sustainability. In: Stegmann R, Brunner G, Calmano W, Matz G (eds) Treatment of contaminated soil. Springer, Berlin, Heidelberg, pp 271-291. https://doi.org/10.1007/978-3662-04643-2_18

34. Hestbjerg H, Willumsen PA, Christensen M et al (2003) Bioaugmentation of tar-contaminated soils under field conditions using Pleurotus ostreatus refuse from commercial mushroom production. Environ Toxicol Chem. https://doi.org/10.1002/ etc. 562022040

35. Adams GO, Fufeyin PT, Okoro SE et al (2015) Bioremediation, biostimulation and bioaugmention: a review. Int J Environ Bioremediat Biodegrad. https://doi.org/10.12691/ijebb-3-1-5

36. Rodriguez-Campos J, Perales-Garcia A, Hernandez-Carballo J et al (2019) Bioremediation of soil contaminated by hydrocarbons with the combination of three technologies: bioaugmentation, phytoremediation, and vermiremediation. J Soils Sediments. https://doi.org/10.1007/s11368-018-2213-y

37. Cafaro V, Izzo V, Scognamiglio R et al (2004) Phenol hydroxylase and toluene/o-xylene monooxygenase from Pseudomonas stutzeri OX1: interplay between two enzymes. Appl Environ Microbiol. https://doi.org/10.1128/AEM.70.4.2211-2219.2004

38. Ambrose KV, Tian Z, Wang $Y$ et al (2015) Functional characterization of salicylate hydroxylase from the fungal endophyte Epichloë festucae. Sci Rep. https://doi.org/10.1038/srep10939

39. Allocati N, Federici L, Masulli M, Di llio C (2012) Distribution of glutathione transferases in Gram-positive bacteria and Archaea. Biochimie. https://doi.org/10.1016/j.biochi.2011.09.008

Publisher's Note Springer Nature remains neutral with regard to jurisdictional claims in published maps and institutional affiliations. 